\title{
Finland's experiences in financing education
}

Mohamed Elasmay Mahrouse

Emeritus professor, Faculty of Education, Sohag University.

DOI:

\section{Abstract}

Finland is considered one of the best countries in the world in the efficiency of the educational system, according to the last two assessments for the years 2003 and 2006, which were conducted by the Organization for Economic Cooperation and Development. Finland spends about 8.159 dollars annually on the services provided to every student in the primary stage, while the volume of spending on preparatory and secondary school students amounts to \$ 12.545 and \$ 8.467 dollars annually, respectively. From a review of Finland's experiences in financing education, we draw the following conclusions:

- The Finnish education system is centralized, as it is financed -basic- from the government there.

- By analyzing the educational situation in Finland, it is free at all educational levels, starting from pre-primary education to higher education.

- Between (11\% and 12\%) of the state's general budget and the budgets of Finnish municipalities are spent on education, and that percentage covers free pre-school education, basic education, secondary education, technical education, higher education, continuing education, and higher studies.

- Responsibilities of funding are divided between the federal government and local governments at a rate of $57 \%$ in favor of the federal government, $43 \%$ for local governments, and the percentage of GDP spending on education reached $6.5 \%$.

- In addition to the shared responsibility for financing educational services between the state and local authorities in Finland, there is a pattern of private educational service providers, as they are entitled to receive support from the state to cover the establishment of their own educational institutions.

Key words: Finland's experiences in education, financing in education.

\section{Introduction}

Finland is at the forefront, or one of the first places, in PISA studies, organized by the Organization for Economic Cooperation and Development (OECD) every three years, and since 2000, the PISA program measures the ability of 15-year-old students to master Mathematics, Science and Reading Organization for Economic Co-operation and Development OECD, 2017). 
It is remarkable that Finland's education policy seems to offer all citizens equal opportunities to receive education, regardless of ethnic origin, gender, and financial situation. Education is regarded as a fundamental right for all citizens and is free at all levels: from pre-primary to highere ducation (Researchgate, 2016).

Thus, Finland is the the best - a country rich in intellectual and educational reform has initiated over the years several novel and simple changes that have completely revolutionized their educational system. They outrank the United States and are gaining on Eastern Asian countries (Big, 2018).

\section{The Educational Situation in Finland}

Finland is considered one of the best countries in the world in the efficiency of the educational system, according to the last two assessments for the years 2003 and 2006, which were conducted by the Organization for Economic Cooperation and Development.

It is worth noting that the differences between those with the highest scores and those with the lowest among Finnish students were minimal, and that capacity levels were high in all types of public schools in Finland (Organization for Economic Co-operation and Development OECD, 2017).

According to international assessments, one of the strengths of Finnish schools is the way in which schools support students who have learning difficulties or who need special support, as it is not possible to enroll in any Finnish school without developing some basic skills.

In reading, mathematics and some other fields, Finland's education system is regarded as one of the best in the world, and other nations are striving to emulate its structure of well-paid teachers, plenty of recess time, and less emphasis on homework and tests.

The country's higher education system also sets an example, especially since Finland is one of the few nations left in the world where its own citizens receive higher education completely free (foreign students still have to pay tuition fees, but they are significantly less than those paid in other countries. The Finnish pavilion at this year's Venice Architecture Biennale paid tribute to this with an exhibition in Finland's public library buildings and their role in education (Jessica, 2018).

\section{Finland's experiences in financing education}

In order to analyze the educational situation in Finland, it is clear that it is free in all educational stages, starting from the pre-primary education stage to the higher education stage, where between $(11 \%$ and $12 \%)$ of the state's general budget and Finnish municipal budgets are spent on education, and this percentage covers Free pre-school education, basic education, secondary education, technical education, higher education, continuing education, and postgraduate studies, as well as partly financing free education for adults, which in turn constitutes opportunities for 
lifelong learning in Finland (Organization for Economic Co-operation and Development, 2017).

In addition to this, students can pay fees for some activities practiced in the school, and textbooks, daily meals and transportation are provided free of charge to parents of students in the preprimary and basic education stages. The Ministry of Education and Culture also granted special government subsidies to support education providers in adopting basic education quality criteria. Many programes were launched to ensure the availability of competent and knowledgeable teaching staff. The aim was to increase participation in staff development training, enhance its impact and improve job satisfaction (Education in Finland, 2015).

Thus, the Finnish education system is centralized, as it is funded -basic- from the government there, and yet many local authorities bear a degree of self-financing in pre-primary education, basic education, general and vocational secondary education.

Education in pre-primary and basic education is part of the basic municipal services that receive legal funding from the government, and legal funding from the government depends on the number of children between 6 and 15 years old residing in the municipality and the special circumstances of the municipality.This funding is not specified, and the municipality can determine how to allocate this funding, as the legal funding from the government for basic municipal services amounts to about a third of the costs (Education in Finland, 2015).

But in secondary and higher education, students themselves or their parents buy their own books. Students at the secondary level are entitled to a free meal, and the state subsidizes the meals provided at the higher education stage. Adult education may be the only type of education that requires payment (Education in Finland, 2015). Funding for secondary education and vocational training depends on the number of students provided by the school, in addition to the unit prices determined by the Ministry of Education and Culture.

As for financing university institutions of applied sciences, the government allocates resources in the form of basic funding based on unit prices for each student, project financing and performancebased financing (IECE, 2020).

University institutions of applied sciences also have external funding sources, as educational service providers are encouraged to improve their results in professional training and in funding university institutions of applied sciences through performance-based financing. Finnish universities are independent companies operating under public law or institutions operating under a private law.

Each university, together with the Ministry of Education and Culture, sets practical and specific goals for the university and identifies the necessary resources every three years. The agreement also defines how these goals are monitored and evaluated from the state, and 
universities receive funding from the state (Education in Finland, 2015).

The Ministry of Education and Culture supervises the public sector funded by education, which includes the development of basic curricula through the Finnish National Board of Education and accreditation of teacher training programs, in addition to the presence of agencies affiliated with regional administrations and centers for economic development that supervise education, The local government is responsible for providing basic education, i.e. grades (1-9) in 3100 schools, $45 \%$ of which teach less than 100 students, and despite the presence of a large number of schools that accommodate more students, the Ministry of Education and Culture has provided licenses to the authorities Local, municipal authorities and associations registered to establish schools (Education in Finland, 2015).

Finland spends about 8.159 dollars annually on the services provided to every student in the primary stage, while the volume of spending on preparatory and secondary school students amounts to \$ 12.545 and \$ 8.467 dollars annually, respectively. One of the most important features of Finnish education is the involvement of parents in the educational process, on the basis that education is a collective responsibility. And to ensure the provision of study opportunities for all, there is an integrated system of scholarships and study loans, and financial aid can be granted to study full-time in a secondary school, the second stage, or through enrollment in vocational institutions, or institutions of higher education (World Bank, 2015).

Thus, the funding responsibilities are divided between the federal government and the local governments by $57 \%$ in favor of the federal government and $43 \%$ in the local governments. Public schools, and most of these private schools are religious schools.

In practice, universities 'expenditures are financed from the state's public budget. However, universities also receive other revenues from commercial financing sources through their services to the point that direct government funding ultimately represents about $70 \%$ of these expenditures from the government and local authorities.

The costs of secondary and vocational education are not covered by government subsidies, so the Municipal Fund contributes $43 \%$ of the budget for secondary or vocational education, while the state funds $57 \%$, and there are no fees that students pay for education, but both lunch and health care are provided to students for free (World Bank, 2015).

In addition, every child and youth have the right to receive a high-quality education, regardless of his personal circumstances or limitations of his capabilities, and students are also entitled to receive help when they need it.

These aids include common forms of support for remedial teaching in small groups, individual counseling, and teaching for pupils according to their personal circumstances, even if they are 
studying in the same classroom with other students.

All schools have special education teachers, and almost all schools have visiting teacher assistants to help if there are pupils with special needs. If a student is found to be suffering from permanent learning difficulties, a personal learning plan is prepared for him.

As for pupils who have moderate or slight learning difficulties, they study in the same schools, and even in the same classes, with other students, but schools receive additional financial resources in this case, and students with intellectual disabilities or physical and sensory disabilities, or Those with health or mental problems, studying in their own classes or in schools, and compulsory education lasts for 11 years for some of them (Sala, 2014).

Thus, in Finland, pupils and students generally receive financial and educational support free of charge. In pre-primary and basic education, textbooks and meals are provided daily, in addition to transportation for students who live far from school, and it is free for parents. At the secondary level, students are entitled to a free meal. As for the meals for students of higher education, they are subsidized by the state. To ensure educational opportunities for all, there is an elaborate system of scholarships and study loans provided to students and their parents (Presentation E Book -5 reasons to Finlands success, 2020).
It should be noted that, at the stage of basic education in Finland, most pupils go to public schools, but only less than (2\%) of this age group go to private schools, and most private schools do not differ from their government counterparts, and the Finnish government maintains them well. My role, as it follows the basic national curriculum and professional qualifications requirements of teachers in these schools, and it also receives support to finance its educational activities (Finland, 2019).

\section{Conclusion}

From a review of Finland's experiences in financing education: opportunities, alternatives, and requirements for improving it in its educational institutions, we draw the following conclusions:

- The Finnish education system is centralized, as it is financed -basic- from the government there. However, many local authorities bear a degree of self-financing in pre-primary education, basic education, general and vocational secondary education, as general and vocational education in which training is jointly funded.

- By analyzing the educational situation in Finland, it is free at all educational levels, starting from pre-primary education to higher education.

- Between (11\% and 12\%) of the state's general budget and the budgets of Finnish municipalities are spent on education, and that percentage covers free pre-school education, 
basic education, secondary education, technical education, higher education, continuing education, and higher studies.

- Students can pay fees for some activities practiced in the school.

- Textbooks, daily meals and transportation are provided free of charge to parents of pupils in the pre-primary and basic education stages. And pre-primary education and basic education are part of the basic municipal services that receive funding from the government.

- In secondary and higher education, students themselves or their parents buy their own books. High school students are also entitled to a free meal, and the state subsidizes meals provided at the higher education stage.

- Responsibilities of funding are divided between the federal government and local governments at a rate of $57 \%$ in favor of the federal government, $43 \%$ for local governments, and the percentage of GDP spending on education reached $6.5 \%$.

- One of the most important features of Finnish education is the involvement of parents in the educational process on the basis that education is a collective responsibility.

- To ensure the provision of study opportunities for all, there is an integrated system of scholarships and study loans, and financial aid can be granted for full-time study in secondary schools, or through enrollment in vocational institutions, or higher education institutions.
- In addition to the shared responsibility for financing educational services between the state and local authorities in Finland, there is a pattern of private educational service providers, as they are entitled to receive support from the state to cover the establishment of their own educational institutions.

\section{References}

Big Think, 2018. 10 reasons why Finland's education system is the best in the world.

Education in Finland, 2015. National Board of Education, Ministry of Education and Culture.

Finland, 2019. Finnish National Agency for Education,

https://www.Oph.fi/english/services/faqs/organisat ion_of_education.

IECE - Finland Country Survey Questionnaire, 2020. Financing of inclusive education systems _ European Agency for Special Needs and Inclusive Education EUROPEAN AGENCY for Special Needs and Inclusive Education

https://img.theculturetrip.com/1024x574/smart/wpcontent/uploads/2018/06/34379368861_61b9f3dbf2_k.j pg

Jessica Wood, 2018. Why Finland's Higher Education System Is the Best in the World_files. the University of Helsinki, Finland.

Organization for Economic Co-operation and Development, OECD. (2017).

Researchgate, 2016. publication at:

https://www.researchgate.net/publication/3121741 $\underline{35}$ 
Presentation E Book- 5 reasons to Finlands success 2020.

DOI: 10.13140/RG.2.2.36233.6512

Sala Corbella, 2014. The secret of the nation's success is schools in Finland, https://finland fi /ar / alheatt-walmjtma/sr-njah-alamtt-almdars-fe-fnlnda

World Bank, 2015.The World Economic Forum. 